GLOBAL JOURNAL OF COMMUNITY MEDICINE VOL. 2 NO. 1 \& 2 2009: 13 - 20 COPYRIGHT@ BACHUDO SCIENCE CO. LTD PRINTED IN NIGERIA. ISSN 1597 - 9857

\title{
PRE-HYPERTENSION AND HYPERTENSION IN APPARENTLY HEALTHY ADOLESCENTS IN CALABAR, NIGERIA.
}

\author{
F. ODEY, M. ANAH, V. ANSA, J. OGBECHE, M. MEREMIKWU, AND E. EKANEM
}

(Received 20 August, 2008; Revision Accepted 7 December, 2008)

\begin{abstract}
Hypertension is a major public health burden in sub-Saharan Africa. It has been shown to track from adolescence to adulthood. Pre-hypertension refers to consistent systolic and/or diastolic blood pressure (BP) measurement between $90-<95^{\text {th }}$ percentile, while hypertension is when systolic and/or diastolic $\mathrm{BP} \geq 95^{\text {th }}$ percentile for age and sex. Prehypertension is considered heightened risk for developing hypertension. The aim of this study was to determine the prevalence of hypertension and prehypertension among urban adolescents in Calabar, south eastern Nigeria. This was a cross sectional survey using multistage sampling techniques among adolescents between the ages of $10-18$ years in four secondary schools in Calabar metropolis. Blood pressures and anthropometric measurements were taken and body mass index was calculated. Three hundred and seventy five subjects were assessed, 146 males and 229 females. The prevalence of hypertension was $6.7 \%$, pre-hypertension was $7.5 \%$ and that of obesity was $1.9 \%$. The mean systolic blood pressure (SBP) for males was $114.00 \pm$ $13.04 \mathrm{mmHg}$ while that for females was $115.18 \pm 12.18 \mathrm{mmHg}$. Only the SBP were found to increase significantly with age $(p<0.001)$, though both showed progressive increase with age. The mean diastolic blood pressure (DBP) for males was $62.55 \pm 8.10 \mathrm{mmHg}$ and $63.16 \pm 9.36 \mathrm{mmHg}$ for females. The mean BMI was $18.52 \pm 2.35$ for males and $19.16 \pm 3.60$ for females and increase with age was statistically significant $(p<0.001)$. The prevalence of both hypertension and pre-hypertension in this adolescent population appears high and necessitates public health attention. It is recommended that larger studies in different Nigerian adolescent populations be conducted to determine the prevalence of hypertension nationwide so that early remedial actions may be taken.
\end{abstract}

KEY WORDS: Hypertension, Pre-hypertension, healthy adolescents.

\section{INTRODUCTION}

Epidemiological studies in adults have demonstrated that hypertension is a major health problem in Nigeria and indeed around the world (Akinkugbe 1992). Several workers have demonstrated that the problem is not uncommon among children and adolescents in different parts of the world (Ekanem et al 1995, Fourth Report on management of Blood Pressure in Children and Adolescents 2004). The existence of hypertension among Nigerian children and adolescents has also been reported by several workers (Antia-Obong and Antia-Obong 1991, Ayoola 1979, Ansa et al 2002). It is known that idiopathic hypertension has its basis in internal physiologic derangements that are already present during childhood (Fourth Report on management of Blood Pressure in Children and Adolescents 2004; Lauer et al 1993). Workers in the United States of America, Denmark and India have shown that children with history of hypertension in any or both parents have significantly higher systolic and diastolic blood

F. Odey, Department of Paediatrics, University of Calabar Teaching Hospital, Calabar, Nigeria

M. Anah, Department of Paediatrics, University of Calabar Teaching Hospital, Calabar, Nigeria

V. Ansa, Department of Internal Medicine, University of Calabar Teaching Hospital, Calabar, Nigeria

J. Ogbeche, Department of Biological Sciences, Cross River University of Technology, Calabar' Nigeria

M. Meremikwu, Department of Paediatrics, University of Calabar Teaching Hospital, Calabar, Nigeria

E. Ekanem, Department of Paediatrics, University of Calabar Teaching Hospital, Calabar, Nigeria 
pressures than those with no such family history (Lauer et al, 1984; Lauer et al, 1993). An isolated high childhood systolic blood pressure is also associated with increased risk of high adulthood blood pressure (Lauer et al, 1984; Lauer et al, 1993). Childhood hypertension has been shown not only to increase the risk of coronary heart disease later in life but also to significantly increase the morbidity and mortality during later childhood and early adult years (Lauer et al, 1993). The prevalence of hypertension among adolescents in developed countries is between 0.6-11\% (Adedoyin and Adeniyi, 2001). In the tropics, prevalence of between $3.3-5.5 \%$ has been reported (Antia-Obong and Antia-Obong 1991, Ayoola 1979, Blankson et al 1977) for children and adolescents. In a study in Calabar, Ansa et al (2002) reported the prevalence of $3.6 \%$ among $16-18$ year old adolescents.

An adolescent is known to explore his environment excessively, crave independence and yet lack the inhibition of adulthood (WHO 1999, Nwokocha 1999, Jenkins 2000). Thus, they are exposed to factors that could increase their chances of developing hypertension such as use of contraceptive pill by females (Nwokocha 1999, Jenkins 2000) and anabolic steroids (Jenkins 2000 ) by males for body building to improve appearance and enhanced athletic performance. So far there's paucity of information on the prevalence of hypertension among adolescents in this environment. The aim of this study therefore was to determine the prevalence of hypertension and to correlate it with the body mass index among adolescents in Calabar.

\section{SUBJECTS AND METHODS}

This was a cross-sectional study in apparently healthy adolescents ages between 10 - 18 years in Calabar, southeastern Nigeria. The subjects were from four day-secondary schools in the two local government areas of Calabar metropolis (i.e. Calabar Municipality and Calabar South). Data was collected over two months (December 2003 to January 2004)

\section{STUDY POPULATION}

The population of Calabar was 458,374 of which 82,507 were school-age children in 2003 (NPC 1992). There were 13 Government owned secondary schools in Calabar Municipal L.G.A. and 6 secondary schools in Calabar South L.G.A. with overall population of 23,117 students in the entire Calabar Metropolis during the 2002/2003 school year (Office records and personal communication with the Chairman, Post Primary Management Board, Ministry of Education, Calabar). Of the 19 government owned secondary schools in Calabar metropolis, only 4 had boarding facilities that accommodate less than $5 \%$ of the entire student population. Thus over $95 \%$ of the student population in the government secondary schools in Calabar were non-boarding students.

Sample size was calculated using the formula for determining sample size for studies with population of more than ten thousand; (Araoye 2003)

$$
\mathrm{N}=\frac{\mathrm{Z}^{2} \times \mathrm{P} \times(100-\mathrm{P})}{\mathrm{d}^{2}}
$$

Where $\mathrm{N}=$ minimum sample size required

$Z=$ standard normal deviate set at 1.96

$\mathrm{P}=$ known prevalence of the disease

$d=$ degree of accuracy

A minimum of three hundred and fifteen (315)

subjects were to be recruited for the study.

\section{SAMPLING TECHNIQUES}

Multi-stage sampling technique was used in this study. In the first stage, the schools were stratified into day and boarding schools. Day secondary schools were chosen for this study. The next stage was simple random sampling in which four day secondary schools were chosen by balloting. The third stage of sampling was stratification of students into junior and senior sections based on their classes. The final sampling process involved the use of statistical table of random numbers to recruit students in their various classes using the class registers. This ensured that any student in the school could have been recruited.

Subjects were enrolled in their various schools. Appointments for sampling and enrolment of participants were fixed at the convenience of the school authorities. School records were used to determine the number of students in each class and arm of the class which was used to calculate the number of students to be recruited. Half $(50 \%)$ of the calculated sample size for each school was taken from the junior secondary school classes and the remaining 50\% from the senior secondary school classes. Letters seeking parental consent to enlist the subjects 
were distributed through the selected students. Procedures were explained to participants to allay anxiety. Participants were enrolled in their various classes.

Inclusion criteria were apparently healthy students within $10-18$ years of age, parental consent and willingness of selected students to participate in the study. While students with history of use of drugs that may affect blood pressure or weight such as anti-hypertensives, corticosteroids, glucocorticoids, use of contraceptive pills in females and anabolic steroids were excluded. Willing subjects whose parents/guardians refused to give consent as well as unwilling subjects whose parents gave consent were also excluded. A pretested semistructured questionnaire was administered to recruited students. Information obtained from each subject included age at last birthday and this was confirmed from the school records. Other data obtained from the students included gender, class of study and smoking habits as well as height, weight, blood pressure, education level and occupation of both parents.

Anthropometric measurements were taken according to the methods described by Paynter and Parkin (1991). The measurements were taken in the sickbay of the schools. Weight was measured using a calibrated bathroom weighing scale to the nearest $0.5 \mathrm{~kg}$. The bathroom scale has been recommended for use in older children and adolescents where the beam balance is not available (Paynter and Parkin 1991) and has been used with reliable results (Antia-Obong and Antia-Obong 1991 and Andy et al 1985). Subjects were asked to stand on the weighing scale without shoes while wearing light clothes. They were instructed to remain upright on the scale with the upper limbs by the sides of the body, while the weight was read and recorded. It was ensured that the pointer was at the zero mark before measurements were taken for each subject. A standard $40 \mathrm{~kg}$ weight was used to confirm the weight on the measuring scale after every $20^{\text {th }}$ subject to ensure precision.

Height was measured using an erect metric rule placed against a perpendicular wall (Paynter and Parkin 1991). The subjects stood erect, barefooted, heels together against bottom of the wall behind as well as the buttocks, shoulders and head equally touching the wall, and chin raised. They were asked to look straight ahead, to make themselves as tall as they can and to take a deep breath. A head-piece was then made to rest on the head of the subject and held firmly to the wall at right angle as the subject was asked to move from under the head-piece. The height was read from under the headpiece on the calibrated metric rule placed against the perpendicular wall. The weights were confirmed by the lead author on every $20^{\text {th }}$ subject to ensure accuracy.

The Quetelet Index or Body Mass Index (BMI) was also calculated from the height and weight already measured using the formula (Paynter and Parkin 1991).

$$
\text { QI }=\frac{\text { Weight }(\mathrm{kg})}{[\text { Height }(\mathrm{m})]^{2}}
$$

BMI calculated as shown above and plotted on the international BMI charts which have been found suitable for developing countries (Kow 1991).

Obesity was defined as BMI $\geq 95^{\text {th }}$ percentile for age and sex while overweight was defined as BMI greater than $85^{\text {th }}$ but less than $95^{\text {th }}$ percentile for age and sex (Paynter and Parkin 1991). Underweight was similarly defined as BMI below the $5^{\text {th }}$ percentile for age and sex. The table below shows classification of the BMI.

Classification Body Mass Index (for age and sex)

$\begin{array}{ll}\text { Underweight } & <5^{\text {th }} \text { percentile } \\ \text { Normal } & 5-85^{\text {th }} \text { percentile } \\ \text { Overweight } & >85^{\text {th }} \text { but }<95^{\text {th }} \text { percentile } \\ \text { Obesity } & \geq 95^{\text {th }} \text { percentile }\end{array}$

BLOOD PRESSURE: Blood pressure (BP) levels were defined in this study as recommended by the $4^{\text {th }}$ report on the diagnosis, evaluation and treatment of high blood pressure in children and adolescents (Fourth Report on management of BP in Children and Adolescents 2004 ) and reference values computed by Andy et al (1985) for Nigerians in the first two decades of life and summarized as shown below;
Blood pressure level

Normal

Pre-hypertension

Hypertension
Average Systolic and/or Diastolic BP for age and sex $<90^{\text {th }}$ percentile $\geq 90^{\text {th }}$ but $<95^{\text {th }}$ percentile $\geq 95^{\text {th }}$ percentile 
The blood pressure was measured using a standard mercury sphygmomanometer (Accouson, England). The cuff size covered approximately two-thirds of the length of the upper arm with the cuff about $2.5 \mathrm{~cm}$ above the antecubital fossa (Fourth Report on management of BP in Children and Adolescents 2004). The sphygmomanometer cuff was applied evenly and snugly to the upper two thirds of the right arm. The subjects were seated in a room for about 5 minutes, the back was supported, feet on the floor and right arm supported, cubital fossa at heart level. Each reading was taken three times at five minutes interval and the average of the three readings was recorded. Measurements were taken to the nearest $2 \mathrm{mmHg}$. The first, fourth and fifth Korotkoff phases were noted. The first and fourth Korotkoff sounds were taken as the systolic and diastolic pressures respectively as recommended by the $4^{\text {th }}$ report on the diagnosis, evaluation and treatment of high blood pressure in children and adolescents (Fourth Report on management of BP in Children and Adolescents 2004). Measurements obtained were plotted on the BP charts computed for Nigerians in the first two decades of life by Andy et al (1985). Subjects whose SBP and/or DBP were between $90-<95^{\text {th }}$ percentile for age and sex were labeled pre-hypertensive while those whose BP were $\geq 95^{\text {th }}$ percentile for age and sex on the BP charts were described as hypertensive (Andy et al 1985). To ensure quality control in blood pressure measurement, a paediatric cardiologist also measured $\mathrm{BP}$ in a tenth of the sample size and the BP measurements he recorded were comparable to those of other study team members.

ETHICAL ISSUES: The study was approved by the Ethical committee of the University of Calabar Teaching Hospital (UCTH). Permission was also obtained from the Cross River State Ministry of Education to involve students in the state owned secondary schools. Finally, informed consent was also obtained from parents and only willing subjects participated in the study i.e. no form of force or coercion was applied nor matter how subtle.

DATA ANALYSIS: Data were analysed using EPI Info 2002 and Statistical Package for Social Sciences (SPSS) software (version 11.0) by a biostastician. Distributions were described as Mean and standard deviation (SD). The analysis of variance (ANOVA) technique was used for comparison of means of continuous variables, with F-statistic as the test of significance. Odds ratio and chi-square were also computed for categorical variables using the EPI-2002 STATCAL two by two tables. Pearson's correlation coefficient was used to describe the association between the variables and age. The 95\% confidence intervals were determined for correlation co-efficient. The level of statistical significance was fixed at $p<0.05$.

\section{RESULTS}

Four hundred and fifty forms were distributed through the students to their parents for consent. Three hundred and ninety forms were returned with parental consent giving the response rate of $86.7 \%$. A total of 15 students declined participation in spite of parental consent and so were excluded from the study. Data was only collected from the willing students with parental consent. Data analysis was carried out on 375 subjects with complete physical data.

\section{DEMOGRAPHIC CHARACTERISTICS OF STUDY POPULATION}

Age and Sex Distribution: Table I shows age and sex distribution of the subjects. Their ages ranged from $10-18$ years, the median age was 15 years and the mean age $14.67 \pm 1.94$ years. There were $146(38.9 \%)$ males and $229(61.1 \%)$ females giving a male to female ratio of 1:1.6. The median age for the males was 15 years and mean age was $14.68 \pm 2.05$ years while the median age for the females was also 15 years and mean was $14.66 \pm 1.80$ years.

\section{MEAN VALUES OF BLOOD PRESSURE AND BODY MASS INDEX}

The mean systolic blood pressure (SBP), diastolic blood pressure (DBP) and body mass index (BMI) are shown in Table II. Both SBP and DBP showed a progressive increase with age although only the increase in SBP was statistically significant $(p<0.01)$. The SBP ranged from $108.22 \pm 11.64$ at 13 years to $119.92 \pm$ 12.64 at 18 years. The mean DBP ranged from 58.04 at 10 years to 65.54 at 18 years. The BMI increased progressively from $15.82 \pm 1.02$ at 10 years to $20.38 \pm 2.26$ at 18 years and it's increase with age was statistically significant $(p<0.01)$. The mean BMI values for the females was higher than that of the males $(p=0.05)$. 
PREVALENCE OF PRE-HYPERTENSION AND HYPERTENSION

The prevalence of hypertension was $6.7 \%$ (25 of $375)$ and was made up of $6.1 \%$ (9 of 146) males and $7.0 \%$ (16 of 229 ) females (Table III). The difference in the prevalence of hypertension between the sexes was not statistically significant $(p=0.75)$. The prevalence of pre-hypertension was $7.5 \%$ (males $6.8 \%$ and females $7.9 \%$ ), the difference between the sexes was not statistically significant $(p=0.83)$. The prevalence of pre- hypertension was $7.5 \%$ (28 of 375 ), constituting $6.8 \%$ of males and $7.9 \%$ of the females.

\section{PREVALENCE OF OBESITY}

The prevalence of obesity was $1.9 \%$ (7 of 375 ). Five $(2.2 \%)$ females and $2(1.4 \%)$ males were obese (Table IV). The difference in the prevalence of obesity between the sexes was not statistically significant $(p=0.57)$. The proportion of overweight for all the subjects in this study was $2.4 \%$ and was higher in females $(3.4 \%)$ than males $(1.4 \%)$.

Table I: Distribution of Subjects by Gender and Age

\begin{tabular}{cccc}
\hline & Age (years) & Males & Females \\
$\mathrm{n}(\%)$ & $\mathrm{n}(\%)$ & $\begin{array}{c}\text { Total } \\
\mathrm{n}(\%)\end{array}$ \\
\hline 10 & $2(1.4)$ & $2(0.9)$ & $4(1.1)$ \\
11 & $7(4.8)$ & $9(3.9)$ & $16(4.3)$ \\
12 & $17(11.6)$ & $18(7.9)$ & $35(9.3)$ \\
13 & $16(11.0)$ & $33(14.4)$ & $49(13.1)$ \\
14 & $22(15.1)$ & $49(21.4)$ & $71(18.9)$ \\
15 & $33(22.6)$ & $39(17.0)$ & $72(19.2)$ \\
16 & $16(11.0)$ & $36(15.7)$ & $52(13.8)$ \\
17 & $19(13.0)$ & $27(11.8)$ & $46(12.3)$ \\
18 & $14(9.6)$ & $16(6.9)$ & $30(8.0)$ \\
\hline \multirow{2}{*}{ Total } & $146(38.9)$ & $229(61.1)$ & $375(100)$ \\
\hline
\end{tabular}

Table 2: Mean Values of Blood Pressure and Body Mass Index by Age

\begin{tabular}{|c|c|c|c|c|c|c|c|c|c|c|c|}
\hline & & & $\mathrm{Age}$ & e (years) & & & & & & ANOVA & \\
\hline Variable & $\begin{array}{c}10-11 \\
n=4\end{array}$ & $\begin{array}{l}11-12 \\
n=16\end{array}$ & $\begin{array}{l}12-13 \\
n=35\end{array}$ & $\begin{array}{l}13-14 \\
n=49\end{array}$ & $\begin{array}{l}14-15 \\
n=71\end{array}$ & $\begin{array}{r}15-16 \\
n=72\end{array}$ & $\begin{array}{l}16-17 \\
n=52\end{array}$ & $\begin{array}{l}17-18 \\
n=46\end{array}$ & $\begin{array}{l}18-19 \\
n=30\end{array}$ & (F.stat) & $p$ \\
\hline SBP MEAI & N 111.54 & 110.58 & 3111.32 & 108.22 & 2111.46 & 117.14 & 4117.72 & 117.52 & 119.92 & 5.01 & $0.001^{*}$ \\
\hline SD & 6.04 & 11.62 & 13.64 & 11.64 & 11.46 & 11.44 & 13.58 & 11.34 & 12.64 & & \\
\hline DBP MEAI & N 58.04 & 61.62 & 62.32 & 60.28 & 64.26 & 63.12 & 62.24 & 64.18 & 65.54 & 1.47 & 0.17 \\
\hline SD & 4.32 & 7.86 & 10.04 & 7.36 & 8.38 & 8.46 & 10.30 & 10.34 & 7.66 & & \\
\hline BMI MEAN & V 15.82 & 17.58 & 17.04 & 17.52 & 18.58 & 19.44 & 18.22 & 19.76 & 20.38 & 6.99 & $0.001^{*}$ \\
\hline SD & 1.02 & 2.28 & 3.80 & 3.18 & 3.20 & 3.52 & 2.32 & 2.04 & 2.26 & & \\
\hline
\end{tabular}

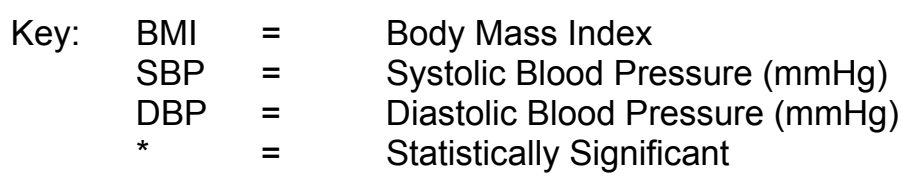


Table 3: Distribution of Pre-hypertension and Hypertension

\begin{tabular}{|c|c|c|c|c|c|c|c|c|}
\hline & \# & $\begin{array}{l}\text { Male } \\
(n=146) \\
\% \text { prev }\end{array}$ & \# & $\begin{array}{c}\text { Female } \\
(n=229) \\
\% p r e v\end{array}$ & \# & $\begin{array}{l}\text { TOTAL } \\
\text { n=375) } \\
\% \text { prev }\end{array}$ & $x^{2}$ & $P$ \\
\hline Pre-Hypertension & 10 & 6.8 & 17 & 7.9 & 28 & 7.5 & 0.04 & 0.83 \\
\hline $\begin{array}{c}\text { Mixed Systolic \& Diastolic } \\
\text { hypertension }\end{array}$ & 7 & 4.8 & 13 & 5.6 & 20 & 5.3 & 0.14 & 0.71 \\
\hline Isolated Systolic hypertension & 1 & 0.7 & 2 & 0.9 & 3 & 0.8 & 0.04 & 0.84 \\
\hline Isolated Diastolic hypertension & 1 & 0.7 & 1 & 0.4 & 1 & 0.5 & 0.10 & 0.74 \\
\hline Total subjects with hypertension & 9 & 6.1 & 16 & 7.0 & 25 & 6.7 & 0.10 & 0.75 \\
\hline
\end{tabular}

$\begin{array}{lll}\text { KEY: } & = & \text { number affected } \\ \% \text { prev } & = & \text { percentage prevalence } \\ X^{2} & = & \text { Chi Square } \\ \mathrm{p} & = & \text { p value }\end{array}$

Table 4: Prevalence of Hypertension and Obesity in the Participants

\begin{tabular}{|c|c|c|c|c|c|c|c|c|c|}
\hline \multirow[t]{2}{*}{ Risk factor } & \multicolumn{2}{|c|}{$\begin{array}{l}\text { Male } \\
(n=146)\end{array}$} & \multicolumn{2}{|c|}{$\begin{array}{l}\text { Female } \\
(n=229)\end{array}$} & \multicolumn{2}{|c|}{$\begin{array}{l}\text { Total } \\
(n=375)\end{array}$} & \multirow[t]{2}{*}{$\begin{array}{l}\text { Odds Ratio } \\
(95 \% \mathrm{Cl})\end{array}$} & \multirow[t]{2}{*}{$x^{2}$} & \multirow[t]{2}{*}{$p$} \\
\hline & \# $\%$ & \%prev & \# & $\%$ prev & \# & $\%$ prev & & & \\
\hline $\mathrm{HBP}$ & 9 & 6.1 & 16 & 7.0 & 25 & 6.7 & $1.15(0.51-2.55)$ & 0.10 & 0.75 \\
\hline OBESITY & 2 & 1.4 & 5 & 2.2 & 7 & 1.9 & $0.62(0.08-3.67)$ & 0.32 & 0.57 \\
\hline KEY: & $\begin{array}{l}\text { HBP } \\
\# \\
\% \text { prev } \\
\mathrm{Cl} \\
X^{2} \\
\mathrm{p}\end{array}$ & $\begin{array}{l}= \\
= \\
= \\
= \\
= \\
=\end{array}$ & \multicolumn{6}{|c|}{$\begin{array}{l}\text { Hypertension } \\
\text { number affected } \\
\text { Prevalence in study population } \\
\text { Confidence Interval } \\
\text { Chi Square } \\
\text { p value }\end{array}$} & \\
\hline
\end{tabular}

\section{DISCUSSION}

The prevalence of hypertension in this study was $6.7 \%$ with more female $(7.0 \%)$ than male $(6.1 \%)$ being hypertensives. Although this prevalence is high, it is within the reported literature prevalence of $0.6-11 \%$ in children and adolescents (Adedoyin \& Adeniyi 2001, Ansa et al 2002). Ekanem et al (1995) had reported prevalence of $3.1 \%$ in Adim, a rural community about $100 \mathrm{~km}$ north of Calabar. Their report was also from a cross sectional study. Since the blood pressure of urban dwellers has been shown to be higher than those of rural inhabitants (Adedoyin \& Adeniyi 2001), it is not surprising that the prevalence is higher in these urban adolescents than that from a rural community (Ekanem et al 1995). Although, blood pressures of these adolescents couldn't be repeated, (a limitation that could affect the interpretation of this study), the findings support the global trend of rising prevalence of hypertension among adolescents (Fourth Report on management of BP in Children and Adolescents 2004, Kitai et al 2007 and Murtner et al 2004.).

The prevalence of pre-hypertension in this study is $7.5 \%$ although this value is lower than the $11.1 \%$ reported by Ostrowska-Nawarycz et al (2007) from Poland and $9.5 \%$ reported by McNiece et al (2007) among USA adolescents in Houston schools respectively. In the study from Poland (Ostrowska-Nawarycz et al 2007), the prevalence of overweight was $15.1 \%$ while obesity was $3.7 \%$ compared to that of $1.9 \%$ seen among adolescents in this study. Also the report from Poland involved both children and adolescents unlike this study which was limited to adolescents. The prevalence of overweight was $18.1 \%$ (prevalence of obesity was not reported) in the study from Houston. Thus the higher level of obesity partly explains the difference in the prevalence of pre-hypertension between these 
studies. In a national database study which reviewed the blood pressure of over 400,000 subjects in Israel (Kitai et al 2007) $>12 \%$ of adolescents were pre-hypertensive and this frequency should not be overlooked. When tracked, many of these pre-hypertensives went on to develop hypertension (Murtner et al 2004).

This study shows a significant progressive increase in SBP from 10 to 18 years of age. The mean DBP on the other hand did not show significant increase with age. This is in keeping with work done among Nigerian School children in Ibadan (Antia-Obong and Antia-Obong 1991). The findings of this study are consistent with other studies that found no significant difference in BP of adolescents between the genders (Fourth Report on management of BP in Children and Adolescents 2004; Antia-Obong and Antia-Obong 1991 and Ayoola 1979).

Comparison of blood pressure between studies is compounded by the various procedures for obtaining its measurements among different investigators. Some investigators record casual BP while others ensure that basal BP measurements are obtained. Some define DBP as the phase IV Korotkoff sound while others take DBP as phase V. In this study the phase IV of Korotkoff sound was used to determine the DBP because in some children the $5^{\text {th }}$ korofkoff sound continues to $0 \mathrm{mmHg}$ (Fourth Report on management of BP in Children and Adolescents 2004). The mean SBP of $114.60 \pm$ $12.62 \mathrm{mmHg}$ reported in this study is higher than $106.5 \pm 11.8 \mathrm{mmHg}$ (Antia-Obong and AntiaObong 1991) and $104.4 \pm 11.7 \mathrm{mmHg}$ (Ayoola 1979) reported by some studies on Nigerian adolescents in urban settings. The mean diastolic BP of $62.6 \pm 8.1 \mathrm{mmHg}$ reported in this study is similar to $61 \pm 9 \mathrm{mmHg}$ obtained by Ayoola (1979) among adolescents but lower than the $71.6 \pm 8.0 \mathrm{mmHg}$ reported by Antia-Obong and Antia-Obong (1991) among school children. The present study as well as the other studies (AntiaObong and Antia-Obong 1991, Ayoola 1979) cited above used the $4^{\text {th }}$ Korotkoff sound to define DBP hence it is unlikely that technique alone could explain the difference noticed. The DBP obtained in the present study is comparable to that reported by Ayoola (1979) which was also on adolescents.

In this study, we allayed anxiety by explaining the procedures to participants. We also used familiar environment to measure the $\mathrm{BP}$, all in an effort to reduce the effect of 'white coat hypertension'.
While prevalence of obesity is $\geq 15 \%$ in North America and Europe, it is not yet a problem among adolescents in this environment. It may pose some threat in the near future with increase consumption of soft drinks, junk food and lack of exercises (Ansa et al 2002). We speculate that provision of school meals should impact positively on the nutritional status of school children in this environment as it has done in other parts of the world.

\section{CONCLUSION}

We conclude that the prevalence of both pre-hypertension and hypertension among adolescents in this population is high. Efforts should be put in place to institute measures that will pick up these conditions early. Measures to treat those already affected should also be intensified. It is recommended that collaborative studies be carried out with larger samples sizes to confirm the findings of this study. We recommend physical exercises for adolescents by ensuring that provision is made for it in the school curriculum. We also recommend the incorporation of blood pressure measurements into routine assessment of adolescents when they attend clinics.

\section{REFERENCES}

Adedoyin, O. T and Adeniyi, A., 2001. Prevention of hypertension in children in the tropics. African Health J 23:16-18.

Akinkugbe, O. O., 1992. Non-Communicable Diseases in Nigeria. Series 1. Federal Ministry of Health and Human Services, Lagos pp1-12.

Andy, J. J., Ladipo, G. O. A., Owolabi, S. P., Teniola, S. O., Ajayi, A. A., Akinola, N. O. and Morakinyo, O., 1991. Blood Pressure Distribution of Nigerians in the First Two Decades of life. Annals Tropical Paediatrics 5:113118.

Ansa V. O., Odigwe C. O. and Ekanem E. E., 2002. Pattern of Blood Pressure in Urban Nigerian Adolescents - Experience from South-Eastern Nigerian. Global Journal of Medical sciences 1:1-8.

Antia-Obong, O. E. and Antia-Obong, L.E., 1991. Arterial Blood Pressure of Nigerian 
Urban/Rural school children. Nigerian $\mathrm{J}$ Paediatrics 18:3-11.

Araoye, M. O., 2003. Research methodology with statistics for health and social sciences. Ilorin: Nathadex Publishers 117pp.

Ayoola, E. A., 1979. Prevalence of adolescent Hypertension in Nigeria. Nigerian $J$ Paediatrics 6:18-26.

Blankson, J. M., Larbi, E. B., Pobbe, J. O. M., Pole, D. J. and Ikeme, A. C., 1977. Blood pressure levels in African children. $\mathrm{J}$ Chronic Disease 30:735-743.

Ekanem, E. E., Ejezie, G. C., Asindi, A. A. and Antia-Obong, O. E., 1995. Urinary symptoms and blood pressure of children with schistosoma haematobium infection in South-Eastern Nigeria. East African Medical J 72: 486-489.

Jenkins, R. R., 2000. Special health problems during adolescence. In: Behrman RE, Kliegman RM, Jenson HB (ed). Nelson textbook of Pediatrics. Philadelphia: WB Saunders Company pp553-587.

Kitai, E., Vinker, S., Halperin, E., Meidan, A. and Grossman, E., 2007. Pre-Hypertension is a common phenomenon: National Database Study. Israel Medical Association J 9:8-11.

Kow, F., Geissler C. and Balasubramaniam E., 1991. Are International Anthropometric Standards Appropriate for Developing Countries? J Tropical Paediatrics 37: 3744.

Lauer, R .M. and Clarke, W. R., 1984. Childhood risk factors for high adult blood pressure. The Muscatine study. Paediatrics 84: 633-641.

Lauer, R. M., Clarke, W. R., Mohaney, L. T. and Witt, J., 1993. Childhood predictor for high adult blood pressure: The muscatine study. Paediatric Clinics North Amercan 40: 2340.
McNiece, K. L., Poffenbarrger, T. S., Turner, J. L., Franco, K. D., Sorof, J. M. and Portman, R. J., 2007. Prevalence of Hypertension and PreHypertension among Adolescents. J Pediatrics 150;640-644.

Murtner, P., He J., Cutler, J. A., Wildman, R. P. and Whelton, P. K., 2004. Trends in blood pressure among children and adolescents. J American Medical Association 291:2107-2113.

National Expert Committee on NonCommunicable Disease (NCD) in Nigeria, 1977. Final Report of a National Survey. Nigeria Federal Ministry of Health.

National Population Commission, NPC Lagos, Nigeria, 1992. Census News 3;5-9.

Nwokocha, A. R. C., 1999. Adolescence and its associated problems. In: Azubuike J. C. and Nkanginieme K. E. O., (Editors). Paediatrics and Child health in a tropical region. Owerri, African Educational Services pp97-109.

Ostrowska-Nawarycz, L. and Nawarycz, T., 2007. Prevalence of excessive body weight and high blood pressure in children and adolescents in the city of Łódź. Kardiol Pol. 65;1079-1087.

Paynter, A. S. and Parkin, M., 1991. Growth in childhood. In: Stanfield P, Brueton M., Chan M., Parkin M. and Waterston T. (editors). Diseases of children in the subtropics and tropics. London: Edward Arnold 254-270.

The Fourth Report on the Diagnosis, Evaluation and Treatment of High Blood Pressure in Children and Adolescents, 2004. National High Blood Pressure Education Program Working Group on High Blood Pressure in Children and Adolescents. Paediatrics 114:555-576.

WHO., 1999. Programing for Adolescent health and development. WHO Tech Rep Series, 886 WHO, Geneva. 